\title{
LA INTERPRETACIÓN FENOMENOLÓGICA DE LA “TRIPLE SÍNTESIS" DE KANT EN KANT Y EL PROBLEMA DE LA METAFÍSICA DE MARTIN HEIDEGGER
}

\author{
The phenomenological interpretation of Kant's "threefold synthesis" in Martin Heidegger's \\ Kant and the problem of the Metaphysics \\ Nicolás Vargas Carlier \\ Universidad Diego Portales, Santiago, Chile \\ estebanicolas@hotmail.com
}

\section{Resumen}

El siguiente ensayo tiene como objetivo analizar la interpretación fenomenológica de Martin Heidegger de la función de la imaginación pura (o trascendental) en la triple síntesis de Immanuel Kant -según la primera edición de la Crítica de la razón pura. En la primera parte, revisaremos la triple síntesis en términos analíticos, con el fin de situar la función de la imaginación trascendental. En la segunda parte, discutiremos la interpretación específica de la imaginación trascendental en Kant y el problema de la Metafísica de Martin Heidegger. ¿Hasta qué punto la interpretación fenomenológica de Martin Heidegger contraviene los fundamentos de la filosofía trascendental?

Palabras clave: fenomenología, triple síntesis, imaginación trascendental, Kant, Heidegger

\begin{abstract}
The following essay aims to analyze Martin Heidegger's phenomenological interpretation of the function of pure (or transcendental) imagination in Immanuel Kant's threefold synthesis -according to the first edition of the Critique of pure reason. In the first part, we will review the threefold synthesis in analytical terms, in order to place the function of the transcendental imagination. On the second part, we will discuss the specific interpretation of the transcendental imagination in Martin Heidegger's Kant and the Problem of Metaphysics. To what extent does Martin Heidegger's phenomenological interpretation contravene the foundations of transcendental philosophy?
\end{abstract}

Keywords: Phenomenology, threefold synthesis, trascendental imagination, Kant, Heidegger

Fecha de Recepción: 30/11/2018 - Fecha de Aceptación: 30/12/2018 


\section{Introducción}

Si tuviéramos que señalar un período en el que la filosofía trascendental kantiana fue especialmente relevante para Martin Heidegger, este sería, sin lugar a dudas, el período comprendido entre los años 1925 y 1929. De modo general, podemos sostener que durante esos años, existe un profundo interés de Martin Heidegger por la filosofía kantiana. Como muestra de esto, bastaría con mencionar las referencias a Kant durante este período: en sus cursos de Lógica, La interpretación fenomenológica de la Crítica de la razón pura, Los Problemas Fundamentales de la Fenomenología, en el índice y el desarrollo de Ser y Tiempo, Introducción a la Filosofía y, finalmente, su libro publicado en 1929, Kant y el problema de la Metafísica ${ }^{1}$. Durante estos años, el pensamiento de Heidegger estará marcado por el desarrollo de una lectura fenomenológica de los elementos de la filosofía trascendental que se encuentran en la primera edición de la Crítica de la razón pura.

Más allá del gran número de objeciones de la que su interpretación ha sido objeto $^{2}$ podemos señalar, de manera general, que los puntos claves de su reinterpretación se centran en tres temas específicos: 1) un análisis detallado del capítulo del Esquematismo de la primera edición de la Crítica de la razón pura, 2) un análisis específico del papel de la imaginación pura (o trascendental) en la triple síntesis -descrita según la redacción sobre la Deducción de los conceptos puros del Entendimiento de la primera edición de la Crítica- y 3) el énfasis en la preeminencia del Tiempo sobre la Apercepción Trascendental en la primera edición de la primera Crítica.

El siguiente ensayo tiene como objetivo revisar el segundo punto en cuestión; i.e., analizar el interés de Martin Heidegger por la función de la

\footnotetext{
${ }^{1}$ El listado de obras de Martin Heidegger dedicadas (en parte o en su totalidad) a Kant es extenso: Logik. Die Frage nach der Wahrheit [GA 21] (Winter Semester 1925-1926), Geschichte der Philosophie von Thomas von Aquin bis Kant [GA 23] (Winter Semester 1926-1927), Die Grundprobleme der Phänomenologie [GA 24] (Summer Semester 1927), Phänomenologische Interpretation von Kants Kritik der reinen Vernunft [GA 25] (Winter Semester 1927-1928) y Einleitung in die Philosophie [GA 27] (Winter Semester 1928-1929). Más tarde, entre los años 1930-1935 encontramos dos leciones en Friburgo: Vom Wesen der menschlichen Freiheit. Einleitung in die Philosophie [GA 31] (Summer Semester 1930) and Die Frage nach dem Ding. Zu Kants Lehre von den transzendentalen Grundsätzen [GA 41] (Winter Semester 1935-1936). Y finalmente, encontramos la última referencia convincente a la filosofía de Kant en las conferencias denominadas el Seminario de Le Thor en 1969.

${ }^{2}$ La bibliografía sobre las objeciones a la interpretación heideggeriana de la filosofía trascendental es muy extensa. Refiero aquí a la lectura de algunos destacados comentaristas: Cassirer (GA3, 113 ss.), Odebrecht (GA 3, 297 ss), Dieter Henrich (1955), Marjorie Greene (1957, 66-7), Karl Löwith (1960, 78), Thomas Langan (1962, xii), Richardson (1967, 159), Shreover (1984, 6), Kisiel (1993, 451,458), van Buren (1994, 366-7), Daniel Dahlstrom (2001, 435 ss), Beatrice Longuenesse (2001) y Han-Pile (2005) -entre otros.
} 
imaginación pura (o trascendental) en la triple síntesis, según la redacción de la sección titulada Deducción de los conceptos puros del Entendimiento en la primera edición de la Crítica. Para cumplir con este objetivo, en la primera parte de este ensayo, revisaremos la triple síntesis kantiana en términos analíticos, con el fin de situar la función específica de la imaginación trascendental, de acuerdo a la primera edición de la Crítica de la razón pura. Una vez logrado este objetivo, nos referiremos a la interpretación específica de la imaginación trascendental en Kant y el problema de la Metafísica (Kantbuch) de Martin Heidegger. La pregunta que quisiera presentar aquí, es la siguiente: ¿hasta qué punto la interpretación fenomenológica de Martin Heidegger contraviene los fundamentos de la filosofía trascendental?

\section{La deducción de los conceptos puros del entendimiento y la triple síntesis en la primera edición de la Crítica de la razón pura}

La sección sobre la Deducción de los conceptos puros del entendimiento de la primera Crítica presenta, desde su inicio, un argumento que resultará primordial para la posterior interpretación heideggeriana de la filosofía trascendental:

Cualquiera que sea la procedencia de nuestras representaciones, bien sean producidas por el influjo de las cosas exteriores, bien sean resultado de causas internas, lo mismo si han surgido a priori que si lo han hecho como fenómenos empíricos, pertenecen, en cuanto modificaciones del psiquismo, al sentido interno $\mathrm{y}$, desde este punto de vista, todos nuestros conocimientos se hallan, en definitiva, sometidos a la condición formal de tal sentido, es decir, al tiempo. En él han de ser todos ordenados, ligados y relacionados. Esto es una observación general que debe tomarse como base imprescindible de lo que sigue (Crítica de la razón pura: A99 -el énfasis es mío) ${ }^{3}$

Según la cita anterior, la síntesis interna (ya sea de la facultad de la imaginación o del entendimiento) debe ser considerada como un proceso que está dispuesto bajo la mera condición formal del tiempo. El tiempo, por lo tanto, confiere un sentido originario desde donde surge todo conocimiento a priori ${ }^{4}$. Teniendo presente la originariedad del tiempo en la génesis del conocimiento, podemos argumentar que

\footnotetext{
3 “Unsere Vorstellungen mögen entspringen, woher sie wollen, ob sie durch den Einfluß äußerer Dinge oder durch innere Ursachen gewirkt sind, sie mögen a priori oder empirisch als Erscheinungen entstanden sein: so gehören sie doch als Modificationen des Gemüths zum innern Sinn, und als solche sind alle unsere Erkenntnisse zuletzt doch der formalen Bedingung des innern Sinnes, nämlich der Zeit, unterworfen, als in welcher sie insgesammt geordnet, verknüpft und in Verhältnisse gebracht werden müssen. Dieses ist eine allgemeine Anmerkung, die man bei dem folgenden durchaus zum Grunde legen muß" (Crítica de la razón pura: A99)

${ }^{4} \mathrm{Al}$ respecto Rosales $(2009,181)$ señala: "la primera síntesis pura del tiempo ha de ser la condición universal de posibilidad de toda otra síntesis, pura o empírica, de la imaginación. En vista de esa, su más alta universalidad, ella debe ser llamada trascendental".
} 
existe una preeminencia de la intuición pura del tiempo por sobre el espacio ${ }^{5}$. Ahora bien, sin una síntesis a priori de las impresiones sensibles, no podría surgir la unidad de la consciencia. Por lo tanto, sin una síntesis a nivel puro, no habría la posibilidad de conocer objetos empíricos -ni tampoco de tener experiencia alguna.

De acuerdo a la primera edición de la Crítica de la razón pura, las fuentes subjetivas que posibilitan el conocimiento son tres: el sentido, la imaginación y la apercepción ${ }^{6}$. La triple síntesis, descrita por la deducción de los conceptos puros del entendimiento, unifica las sensaciones empíricas provenientes de la sensibilidad y las relaciona con la diversidad pura del tiempo y las categorías.

Comencemos analizando la síntesis de la aprehensión y su rol en la triple síntesis. La síntesis se define en la deducción de los conceptos puros del entendimiento de la siguiente forma:

Cada intuición contiene en sí una pluralidad que, sin embargo, no sería representada como tal si la mente no distinguiera el tiempo en la serie de impresiones sucesivas, pues cada representación, en cuanto contenida en un momento, no puede ser otra cosa que unidad absoluta. Para que esta pluralidad se vuelva unidad de la intuición (como en la representación del espacio) es necesario primero recorrer la pluralidad y entonces reunirla. Llamo a esta acción síntesis de la aprehensión $(\mathrm{A} 99)^{7}$

La síntesis de la aprehensión une a la multiplicidad sensorial-que aparece en el continuo fluir del tiempo- a través de la facultad de la sensibilidad. En los

\footnotetext{
${ }^{5}$ Esto ya ha sido esbozado anteriormente en la Estética trascendental. A partir de las afirmaciones expuestas en este apartado, podemos extraer cuatro conclusiones: 1) Espacio y Tiempo son formas puras de la intuición, 2) la intuición pura del espacio es una condición necesaria para toda intuición externa. 3) la intuición pura del tiempo es una condición necesaria para toda intuición: tanto externa como interna. Finalmente, 4) las intuiciones puras de espacio y tiempo otorgan las condiciones fundamentales (junto con la función del entendimiento) para todos los juicios sintéticos a priori de la Matemática.

${ }^{6}$ Son tres las fuentes subjetivas de conocimiento en las que se basa la posibilidad de la experiencia en general y del conocimiento de los objetos de esa misma experiencia: el sentido, la imaginación y la apercepción. El sentido representa empíricamente los fenómenos en la percepción, la imaginación en la asociación (y en la reproducción), la apercepción en el reconocimiento (Crítica de la razón pura: A115). Aunque Kant, en ninguna parte, señala que dichas síntesis dependan de estas facultades del alma. Sin embargo, la síntesis es atribuida en otros pasajes a la facultad de la imaginación; específicamente en A78 y A120.

7 "Jede Anschauung enthält ein Mannigfaltiges in sich, welches doch nicht als ein solches vorgestellt werden würde, wenn das Gemüth nicht die Zeit in der Folge der Eindrücke auf einander unterschiede: denn als in einem Augenblick enthalten kann jede Vorstellung niemals etwas anderes als absolute Einheit sein. Damit nun aus diesem Mannigfaltigen Einheit der Anschauung werde (wie etwa in der Vorstellung des Raumes), so ist erstlich das Durchlaufen der Mannigfaltigkeit und dann die Zusammennehmung desselben nothwendig, welche Handlung ich die Synthesis der Apprehension nenne" (A99).
} 
múltiples y sucesivos espacios y tiempos, se establece una separación que toma una forma de sucesión. La actividad de la síntesis de aprehensión remite a la producción de imágenes (Bilder). Se determina, así, que existe una facultad activa que sintetiza la multiplicidad de los fenómenos: aquella es la imaginación, pues "la imaginación tiene que reducir a una sola imagen la diversidad de la intuición" $(\mathrm{A} 120)^{8}$.

Una vez que la síntesis de la aprehensión ha sintetizado en imágenes las aprehensiones empíricas, Kant señala: “tiene que haber algo que, por ser el fundamento a priori de su unidad sintética indispensable, haga posible esa reproducción de los fenómenos" (A101); más adelante afirma: "nos veremos obligados a suponer una síntesis trascendental pura de la imaginación, una síntesis que, a su vez, servirá de base a la posibilidad de toda experiencia, ya que ésta, en cuanto tal experiencia, presupone necesariamente la reproductibilidad de los fenómenos" (A101). La síntesis de la reproducción, entonces, actúa sobre la unidad de la imagen posibilitada por la síntesis de la aprehensión.

La síntesis de la aprehensión es incapaz de recorrer la unidad que ella misma ha alcanzado. Para poder hacerlo, sería necesario que las sensaciones aprehendidas en la intuición pura del tiempo queden registradas. Esta es, pues, esencialmente, la labor que ejecuta la síntesis de la reproducción. Sin el reconocimiento que posibilita una retención progresiva del recorrido de una imagen -i.e., su reproducción- tendríamos sólo la posibilidad de la consciencia de un instante interminable. Por lo tanto, la posibilidad de comprensión de una intuición empírica, está dada por la inseparable unión entre la síntesis de la aprehensión y la función de la síntesis de la reproducción (A102).

Una vez lograda la reproducción de una imagen y su identificación singular -por medio de la actividad de las síntesis de la aprehensión y reproduccióntenemos un problema análogo al anterior: si no fuéramos capaces de reconocer aquello que ya hemos aprehendido anteriormente, nuestra consciencia permanecería en una serie infinita de reproducciones de sensaciones siempre nuevas. Sin embargo, nuestras facultades internas sí tienen la capacidad de reconocer e identificar sensaciones pasadas. Ya sea una figura extravagante, un sonido o un color, podemos afirmar que existen intuiciones que reconocemos y

\footnotetext{
${ }^{8}$ En A120 Kant señala en una nota al pie el importante respecto al rol de la imaginación en el conocimiento: "No ha habido todavía sicólogo que cayera en la idea de que la imaginación constituye un indispensable ingrediente de la misma percepción. Ello se debe, por una parte, a que se ha circunscrito esta facultad a las meras reproducciones y, por otra, a la creencia de que los sentidos no sólo nos suministran impresiones, sino que incluso las combinan y producen imágenes de los objetos. Es indudable que, para llevar a cabo esta tarea, se requiere algo más que la receptividad de las impresiones, es decir, hace falta una función que las sintetice" (Crítica de la razón pura: A120 -nota al pie).
} 
asociamos con aprehensiones anteriores. Pues bien, el reconocimiento que identifica y conserva las aprehensiones anteriores comprende un reconocimiento puro: esta es la tarea de la síntesis del reconocimiento de la representación en el concepto. Kant es enfático en torno a la identificación del conocimiento con los conceptos:

Todo conocimiento requiere un concepto, por muy imperfecto u oscuro que éste sea. Pero el concepto es siempre, por su forma, algo universal y que sirve de regla. Así, el concepto de cuerpo sirve de regla, en virtud de la unidad de lo diverso pensado a través de él, al conocimiento de los fenómenos externos. Y sólo puede constituir una regla para las intuiciones representando en los fenómenos dados la necesaria reproducción de su diversidad y, por tanto, la unidad sintética en la consciencia de los mismos. Así, cuando percibimos algo exterior a nosotros, el concepto de cuerpo requiere la representación de la extensión y, consiguientemente, las de impenetrabilidad, forma, etc. $(\mathrm{A} 106)^{9}$.

La consciencia de la mismidad y unidad en el proceso de las síntesis de la aprehensión y de reproducción requiere de la posibilidad de una síntesis constante y estable que fundará toda intuición (pura y empírica) y se constituirá como el principio fundamental del conocimiento. Aquel principio es el de la apercepción. En la apercepción, entonces, descansa la objetividad del conocimiento:

Consiguientemente, la originaria e ineludible conciencia de identidad del yo es, a la vez, la conciencia de una igualmente necesaria unidad de síntesis de todos los fenómenos según conceptos, es decir, según reglas que no sólo tienen que permitir reproducirlos, sino que, además, fijan así un objeto a la intuición de los mismos, esto es, determinan el concepto de algo donde se hallan necesariamente enlazados. En efecto, el psiquismo no podría pensar, y menos a priori, la identidad del yo en medio de la diversidad de sus representaciones, si no tuviera presente la identidad de su acto, identidad que somete toda síntesis de aprehensión (que es empírica) a una unidad trascendental y que hace posible su interconexión según reglas a priori (A108) ${ }^{10}$.

\footnotetext{
9 "Alles Erkenntniß erfordert einen Begriff, dieser mag nun so unvollkommen oder so dunkel sein, wie er wolle; dieser aber ist seiner Form nach jederzeit etwas Allgemeines, und was zur Regel dient. So dient der Begriff vom Körper nach der Einheit des Mannigfaltigen, welches durch ihn gedacht wird, unserer Erkenntniß äußerer Erscheinungen zur Regel. Eine Regel der Anschauungen kann er aber nur dadurch sein, daß er bei gegebenen Erscheinungen die nothwendige Reproduction des Mannigfaltigen derselben, mithin die synthetische Einheit in ihrem Bewußtsein vorstellt. So macht der Begriff des Körpers bei der Wahrnehmung von Etwas außer uns die Vorstellung der Ausdehnung und mit ihr die der Undurchdringlichkeit, der Gestalt etc. nothwendig" (Crítica de la razón pura: A106).

10 "Also ist das ursprüngliche und nothwendige Bewußtsein der Identität seiner selbst zugleich ein Bewußtsein einer eben so nothwendigen Einheit der Synthesis aller Erscheinungen nach Begriffen, d. i. nach Regeln, die sie nicht allein nothwendig reproducibel machen, sondern dadurch auch ihrer Anschauung einen Gegenstand bestimmen, d. i. den Begriff von Etwas, darin sie nothwendig zusammenhängen: denn das Gemüth könnte sich unmöglich die Identität seiner selbst in der Mannigfaltigkeit seiner Vorstellungen und zwar a priori denken, wenn es nicht die Identität seiner Handlung vor Augen hätte, welche alle Synthesis der Apprehension (die empirisch ist) einer
} 
Con respecto a la unidad de la conciencia reflejada en la constitución de un objeto, podemos afirmar que un concepto a priori, que está referido a un objeto empírico, exhibe la unidad a priori de la consciencia. Ésta será la condición trascendental de todo conocimiento a priori: la apercepción trascendental.

Toda necesidad se basa siempre en una condición trascendental. En consecuencia, tiene que haber un fundamento trascendental de la unidad de la consciencia en la síntesis de la diversidad contenida en todas nuestras intuiciones y, por tanto, de los conceptos de objetos en general y, consiguientemente, de todos los objetos de la experiencia. Sin tal fundamento, sería imposible pensar un objeto de nuestras intuiciones, ya que este objeto no es más que el algo cuyo concepto expresa dicha necesidad de síntesis. Esta condición originaria y trascendental, no es otra que la apercepción trascendental. (A106) ${ }^{11}$.

La apercepción trascendental, por lo tanto, es el punto cúlmine de la búsqueda por la condición última de toda experiencia posible. El yo pienso -indicará Kant al inicio del parágrafo $\$ 16$ de la Deducción B- "debe poder acompañar todas mis representaciones, porque de lo contrario ellas no serían nada para mí" (Crítica de la razón pura: B131-132) Existe, entonces, la necesidad de exponer la sucesión de impresiones de la triple síntesis en una misma consciencia, que deberá ser autoconsciente. De otro modo, tendríamos un yo disgregado que sólo sería capaz de representaciones inconexas.

En pocas palabras, sin la condición de una autoconsciencia que unifique las impresiones empíricas, no habría posibilidad alguna de tener experiencia -al menos, tal como la hemos definido hasta aquí: como el reconocimiento de una sucesión de impresiones empíricas en un tiempo determinado. El yo trascendental, es una mera consciencia de que las representaciones sensibles que adquirimos por nuestra sensibilidad y que, además, enlazamos mediante nuestras categorías, a través de la triple síntesis, pertenecen a una única experiencia. El yo trascendental es la mera convergencia originaria de una síntesis a nivel puro que derivará en el conocimiento empírico.

Recapitulemos aquí los puntos más relevantes de la deducción trascendental que hemos revisado de forma analítica ${ }^{12}$ :

transscendentalen Einheit unterwirft und ihren Zusammenhang nach Regeln a priori zuerst möglich macht" (Crítica de la razón pura: A108).

11 “Aller Nothwendigkeit liegt jederzeit eine transcendentale Bedingung zum Grunde. Also muß ein transscendentaler Grund der Einheit des Bewußtseins in der Synthesis des Mannigfaltigen aller unserer Anschauungen, mithin auch der Begriffe der Objecte überhaupt, folglich auch aller Gegenstände der Erfahrung angetroffen werden, ohne welchen es unmöglich wäre, zu unsern Anschauungen irgend einen Gegenstand zu denken: denn dieser ist nichts mehr als das Etwas, davon der Begriff eine solche Nothwendigkeit der Synthesis ausdrückt. Diese ursprüngliche und transscendentale Bedingung ist nun keine andere, als die transscendentale Apperception" (A 106).

12 Véase también: Hartnack. J (2006) Cap. II. 2. La deducción Trascendental. 
1) La intuición pura del tiempo es condición de posibilidad de todo intuir, tanto del intuir interno como del externo.

2) La síntesis pura del tiempo es condición universal de posibilidad de toda síntesis

3) Existe una síntesis a nivel puro entre las formas puras del entendimiento y las impresiones sensibles. Este es el lugar de la triple síntesis.

4) En la triple síntesis se distinguen tres síntesis simultáneas, que expuestas analíticamente son: síntesis de la aprehensión, reproducción y reconocimiento. En la síntesis de la reproducción, la labor de la facultad de la imaginación es esencial para el conocimiento.

5) La triple síntesis a priori presupone una unidad de la consciencia que debe estar a la base de todo conocimiento. Aquella es la apercepción trascendental ${ }^{13}$.

6) La apercepción trascendental es condición necesaria de: 1) la triple síntesis a priori 2) la unidad de las intuiciones empíricas y 3) la formación de conceptos y elaboración de juicios.

\section{Observaciones a la imaginación trascendental en la deducción de las categorías}

La síntesis pura de la imaginación -que luego estará sometida a las formas puras por la función de la facultad del entendimiento para constituir conceptos- se funda en sus propias reglas ${ }^{14}$. Kant se referirá a ella como una síntesis productiva de la imaginación. Tal como señalamos en el argumento número 5 (la triple síntesis a priori presupone una unidad de la consciencia que debe estar a la base de todo conocimiento; aquella es la apercepción trascendental), Kant sostiene que la apercepción trascendental presupone una síntesis a priori; esta síntesis a priori-que refiere a las sensaciones- es el resultado de la facultad de la imaginación en su rol productivo. Ahora bien, si suponemos que esta síntesis a nivel puro es el producto de la

\footnotetext{
${ }^{13}$ En Loses Blatt B12 encontramos una muy enfática frase al respecto: "ningún fenómeno puede significar nada para mí, si no puede al menos tener lugar por medio de la síntesis de la apercepción" (Loses Blatt B12, AA XXIII 19)

${ }^{14}$ Aquí encontramos el lugar en la deducción trascendental de las categorías del concepto de "esquema trascendental". El concepto de esquema trascendental está desarrollado en la Crítica de la razón pura, en el primer capítulo de la Doctrina Trascendental del juicio. El esquema trascendental mediará entre la síntesis de la imaginación y los conceptos. No nos detendremos en explicar este concepto, debido a que -estimo- Kant evita referirse a él en la Deducción de los conceptos puros del entendimiento. Sin embargo, Rosales $(2009,180)$ indica que el pasaje de A103 se debe interpretar como una referencia implícita al concepto de esquema trascendental, que será posteriormente abordado.
} 
imaginación productiva en la sensibilidad, la imaginación en su rol trascendental ${ }^{15}$ (o pura) cumplirá un rol adicional: ella referirá -mediante las categorías- a la síntesis empírica a la unidad sintética de la apercepción. Esto último, remite al rol más explícito de la imaginación en su labor trascendental: ella se instituye como la condición subjetiva del conocimiento, en tanto que es la raíz original de las categorías. En en esta labor de la imaginación donde se prefigura el concepto que enlaza una intuición con las categorías. Luego, mediante la labor del entendimiento, una intuición podrá ser enlazada con un concepto ${ }^{16}$. Podemos argumentar esto, a partir del siguiente párrafo:

Llamamos trascendental a la síntesis de lo diverso en la imaginación <a la síntesis

priori la diversidad. Damos el nombre de trascendental, a la unidad de esa síntesis cuando tal unidad es representada como necesaria a priori en relación con la originaria unidad de la apercepción (A118) 17 .

La imaginación trascendental, entonces, será el resultado de relacionar la síntesis productiva de la imaginación con la unidad de la apercepción. Más específicamente, tal como lo refleja Kant en A119: “En relación con la síntesis de la imaginación, la unidad de la apercepción es el entendimiento; en relación con la síntesis trascendental de la imaginación, esa misma unidad es el entendimiento puro" $^{\prime 18}$.

Ahora bien, en relación con la imaginación trascendental y el conocimiento, revisemos el fragmento de A101:

${ }^{15}$ Así definida: La imaginación es, por tanto, también una facultad de una síntesis a priori por la cual le damos el nombre de imaginación productiva; $y$, en la medida en que ésta no tiene más intención que la unidad necesaria en la misma síntesis en relación con toda multiplicidad del fenómeno, puede denominarse la función trascendental de la imaginación (Crítica de la razón pura: A123).

${ }^{16}$ Así también expone Rosales $(2009,215)$ a la facultad de la imaginación como "la facultad que, a través de un arte oculto en lo profundo del alma humana, hace posible el juicio".

17 "Also bezieht sich die transscendentale Einheit der Apperception auf die reine Synthesis der Einbildungskraft als eine Bedingung a priori der Möglichkeit aller Zusammensetzung des Mannigfaltigen in einer Erkenntniß. Es kann aber nur die productive Synthesis der Einbildungskraft a priori statt finden; denn die reproductive beruht auf Bedingungen der Erfahrung. Also ist das Principium der nothwendigen Einheit der reinen (productiven) Synthesis der Einbildungskraft vor der Apperception der Grund der Möglichkeit aller Erkenntniß, besonders der Erfahrung" (Crítica de la razón pura: A118).

18 "Die Einheit der Apperception in Beziehung auf die Synthesis der Einbildungskraft ist der Verstand und eben dieselbe Einheit beziehungsweise auf die transscendentale Synthesis der Einbildungskraft der reine Verstand. Also sind im Verstande reine Erkenntnisse a priori, welche die nothwendige Einheit der reinen Synthesis der Einbildungskraft in Ansehung aller möglichen Erscheinungen enthalten" (Crítica de la razón pura: A119). 
Tiene, pues, que haber algo que, por ser el fundamento a priori de su unidad sintética indispensable, haga posible esa reproducción de los fenómenos ...nos veremos obligados a suponer una síntesis trascendental pura de la imaginación, una síntesis que, a su vez, servirä de base a la posibilidad de toda experiencia, ya que ésta, en cuanto tal experiencia, presupone necesariamente la reproductibilidad de los fenómenos (A 101) ${ }^{19}$

En la cita anterior, Kant argumentaría que es la imaginación trascendental el principio que debe ser presupuesto como fundamento de toda experiencia. Tal como podemos entrever aquí, el argumento de la deducción de los conceptos puros del entendimiento (de acuerdo a la primera edición de la Crítica) parece conferir una enorme importancia a la actividad productiva de la imaginación en la génesis del conocimiento $^{20}$.

\section{Heidegger y la interpretación de la triple síntesis de la primera edición de la Crítica de la razón pura}

Con el fin de situar la interpretación de Martin Heidegger en la anterior revisión de la triple síntesis de la filosofía trascendental, destacaré dos puntos -siguiendo el esquema de arriba- sobre los que Heidegger centrará su análisis sobre la Deducción de los conceptos trascendentales en la primera edición de la Crítica de la razón pura.

Anteriormente, destacamos seis puntos que podemos obtener de la triple síntesis de la edición A de la primera Crítica. Pues bien, los puntos a los que pondremos especial atención -en vistas de la interpretación de Martin Heidegger son los puntos son 3 y 4: (3) Existe una síntesis a nivel puro entre las formas puras del entendimiento y las impresiones sensibles. Este es el lugar de la triple síntesis. Y (4) En la triple sintesis se distinguen tres síntesis simultáneas, que expuestas analíticamente son: síntesis de la aprehensión, reproducción y reconocimiento. En la síntesis de la reproducción, la labor de la facultad de la imaginación es esencial para el conocimiento.

\footnotetext{
19 "Es muß also etwas sein, was selbst diese Reproduction der Erscheinungen möglich macht, dadurch daß es der Grund a priori einer nothwendigen synthetischen Einheit derselben ist...so ist diese Synthesis der Einbildungskraft auch vor aller Erfahrung auf Principien a priori gegründet, und man muß eine reine transscendentale Synthesis derselben annehmen, die selbst der Möglichkeit aller Erfahrung (als welche die Reproducibilität der Erscheinungen nothwendig voraussetzt) zum Grunde liegt" (A 101).

${ }^{20}$ Hasta aquí he expuesto -de modo general- la función de la imaginación trascendental en la primera edición de la Crítica de la razón pura. La imaginación, es una facultad que además de poseer una síntesis independiente de la facultad del entendimiento, en su uso trascendental, es supuesta como el fundamento de la posibilidad de toda experiencia, ya que ésta presupone necesariamente la reproductibilidad de los fenómenos (A101). Desde luego, las observaciones que he desarrollado en esta sección, no están alejadas de un aspecto polémico. Además de solo referirme a la primera edición de la Crítica de la razón pura, también he tenido el objetivo de introducir la interpretación de Martin Heidegger.
} 
A partir de ambas conclusiones, Heidegger cuestionará la originariedad de la Apercepción trascendental. ¿En qué medida Kant podría afirmar que existe una unidad trascendental anterior a la formación de la forma de una intuición? ¿Existe un aspecto más originario en la mera percepción de un objeto sensible, que la síntesis a priori de las categorías puras? Es más: Kant mismo ha afirmado en la Estética Trascendental que la intuición pura del tiempo es la condición de posibilidad de todo intuir -tanto externo como interno ${ }^{21}$. Entonces, ¿podría existir en la filosofía trascendental una unidad más originaria que aquella determinada por el tiempo? En este punto, Heidegger intenta hallar una instancia más original que la reconocida por el propio Kant; aquella es, la facultad de la imaginación, en tanto que origen de un tiempo originario (A101 -citado arriba).

Siguiendo esta cita, una síntesis trascendental pura de la imaginación estaría a la base de toda experiencia. Ahora bien: ¿podría existir algo más originario que el tiempo para la filosofía trascendental, si nos referimos a los fundamentos de una experiencia sensible? Heidegger, estimo, interpretará aquí lo siguiente: existiría, entre las formas puras del entendimiento y la forma de los objetos sensibles, un vínculo ontológico -y al que el propio Kant parecería admitir en la primera edición de la Crítica- cuya forma original está dada en la intuición pura del tiempo. Por lo tanto, existiría en la filosofía trascendental, un vínculo esencial entre las categorías y el tiempo 22.

Revisemos la interpretación de Heidegger de la triple síntesis de la primera Crítica en GA3. Las síntesis de aprehensión (de las representaciones en la intuición), la reproducción (de las intuiciones en la imaginación) y de reconocimiento, serán identificadas por Heidegger como tres capacidades de la imaginación; i.e.: facultas formandi (Abbilden), facultas imaginandi (Nachbilden) y facultas praevidendi (Vorbilden) -respectivamente. Las tres capacidades son identificadas por Heidegger en un devenir temporal. Esto es, la imaginación sintetiza en su función presente, pasado y

21 "El tiempo es "la forma del sentido interno, del intuir a nosotros mismos y a nuestro estado interior", cuyo primer momento es imaginación y síntesis trascendental. Por estas se comprenden, la permanencia, la sucesión, la simultaneidad, la eternidad, la finitud y la contingencia; que son, a su vez, esquemas de conceptos puros del entendimiento que tienen su uso posible, con referencia a objetos de la experiencia, y sólo mediante estos, pueden llegar a tener significación y sentido lógicoestético y singularidad subjetiva. Según esto, tiempo es sentido interno y existencia (con el espacio) $\mathrm{y}$, en cuanto condición de posibilidad de la experiencia y forma originaria de la sensibilidad se despliega a partir de la actividad de la imaginación que, en cuanto causa de la síntesis, es a su vez consecuencia de la, así llamada por Kant, desconocida raíz común del conocer". Véase: Álvarez W. $(2014,43)$.

22 Por supuesto, cuando Heidegger sostiene que existe en un vínculo entre las categorías y el tiempo en la Crítica de la razón pura, está buscando fundamentar un aspecto útil para su propia ontología fundamental, esto es, un vínculo a nivel ontológico entre Dasein y Tiempo. 
futuro -todos inmediatos- de una intuición. Así presenta Heidegger este aspecto en su Kantbuch:

Pero la intuición pura no puede formar la sucesión pura de la serie de los ahoras si no a condición de ser en sí imaginación formadora, preformadora y reproductora. En consecuencia, el tiempo no debe ser tomado, de ningún modo, y menos aún en sentido kantiano, por un campo cualquiera, en el cual hubiese caído la imaginación a fin de entrar en actividad... Pero esta serie de ahoras no es, de ningún modo, el tiempo en su originareidad. Por el contrario, es la imaginación trascendental quien da nacimiento al tiempo como serie de ahoras y quien, por dar nacimiento a éste, resulta ser el tiempo originario (GA3, 175-6) ${ }^{23}$ (el énfasis es mío)

La pregunta por la posibilidad del conocimiento sintético a priori de la primera Crítica, dirige a Heidegger hacia el análisis de la síntesis de la imaginación trascendental. ¿Por qué? Tal como se señala en la primera Crítica, esta facultad es supuesta como el fundamento de la posibilidad de toda experiencia, ya que ésta, en cuanto tal experiencia, presupone necesariamente la reproductibilidad de los fenómenos (A 101). Para Heidegger, el tiempo originario, en forma de imaginación trascendental, es pura "formación de imagen", "reproducción" y "reconocimiento de las intuiciones" que se generan en la mera receptividad. Sólo una vez unificadas las tres fases temporales de la triple síntesis -en forma de pasado, presente y futuropodemos comprender que la formación de una intuición, por medio de las categorías, es el fundamento último de la fenomenología que podemos encontrar en la primera edición de la Crítica de la razón pura:

La imaginación trascendental, sobre el fundamento de su estructura originaria e indestructible, abre la posibilidad de una fundamentación del conocimiento ontológico y con ello de la metafísica; por eso la primera edición está más cercana al rasgo interno de la problemática de una fundamentación de la metafísica. $(\mathrm{GA} 3,197)^{24}$.

La imaginación trascendental, así interpretada, señala la posibilidad del surgimiento de un tiempo originario; y es en ella donde podemos encontrar el vínculo más elemental entre la posibilidad del conocimiento sintético a priori y la intuición. Así, la validez del empleo de las categorías en la filosofía trascendental,

23 “Die reine Anschauung kann aber das reine Nacheinander der Jetztfolge als solches nur dann bilden, wenn sie in sich ab-, vor- und nachbildende Einbildungskraft ist. Die Zeit darf daher keineswegs, und gerade auch nicht im Kantischen Sinne, als ein beliebiges Feld gedacht werden, an das die Einbil- dungskraft nun einmal zu Zwecken ihrer Betatigimg gleich- sam hingeraten ist...Die transzenden-tale Einbildungskraft vielmehr laßßt die Zeit als Jetztfolge ent-springen und ist deshalb -als diese entspringenlassende- die ursprüngliche Zeit" (GA3, 175-6).

24 "Weil die transzendentale Einbildungskraft aber auf Grund ihrer unzerreißbaren ursprünglichen Struktur die Möglichkeit einer Grundlegung der ontologischen Erkenntnis und damit der Metaphysik eröffnet, deshalb bleibt die erste Auflage dem innersten Zuge der Problematik einer Grundlegung der Metaphysik näher"' (GA3, 197). 
está dada por la formación de una intuición en una imagen que es, a su vez, posibilitada por la reunión de pasado-presente-futuro inmediatos.

La imaginación trascendental, vista desde esta perspectiva, posibilita en su síntesis pura un ahora que marca la génesis del conocimiento ontológico; $\mathrm{o}$, en términos kantianos, la posibilidad del conocimiento sintético a priori.

Ahora bien, en un contexto estrictamente exegético, la interpretación de Heidegger sobre los fundamentos de la primera Crítica contraviene, en términos generales, al menos dos claros corolarios del sistema de la primera Crítica; a saber: a) Heidegger sitúa el concepto de Tiempo e imaginación trascendental en un estatuto analíticamente más originario que la apercepción trascendental y b) la Imaginación pura es la raíz de la trascendencia que reúne originariamente los elementos provenientes de la sensibilidad y entendimiento. Revisemos ambas afirmaciones:

a) Heidegger sitúa el concepto de Tiempo e imaginación trascendental en un estatuto analíticamente más originario que la apercepción trascendental. Consideremos el siguiente párrafo:

Los modos de la síntesis pura - aprehensión pura, reproducción pura, reconocimiento puro- no son tres porque se refieran a los tres elementos del conocimiento puro, sino porque, siendo en sí originariamente uno, forman el tiempo, constituyen la temperación del tiempo mismo. Solamente porque estos modos de la síntesis pura son originariamente uno en la triplicidad unitaria del tiempo, se encuentra en ellos la posibilidad de la unión originaria de los tres elementos del conocimiento puro. $\mathrm{Y}$ por eso también el elemento originariamente unitivo, la imaginación trascendental, en apariencia sólo una facultad intermediaria y media, no es otra cosa que el tiempo originario. Únicamente esta raigambre en el tiempo hace que la imaginación trascendental pueda ser la raíz de la trascendencia. (GA3, 196) ${ }^{25}$ (el énfasis es mío)

Analíticamente, Heidegger sostiene que no podría haber nada más originario que el tiempo. Así, la triple síntesis de la imaginación, se situará en la raíz de todo conocimiento sintético a priori, constituyéndose, ella misma, en fuente de un tiempo originario. Esta afirmación contraviene un claro dictum kantiano: la presuposición de la existencia de la apercepción trcendental como condición

25 “Die Modi der reinen Synthesis - reine Apprehension, reine Reproduktion, reine Rekognition sind nicht deshalb drei an der Zahl, weil sie auf die drei Elemente der reinen Erkenntnis Bezug haben, sondern weil sie, in sich ursprünglich einig, zeitbildend die Zeitigung der Zeit selbst ausmachen. Nur weil diese Modi der reinen Synthesis in der dreifach-einigen Zeit ursprünglich einig sind, liegt in ihnen auch die Möglichkeit der ursprünglichen Einigung der drei Elemente der reinen Erkenntnis. Deshalb ist aber auch das ursprünglich Einigende, das scheinbar nur vermittelnde Zwischenvermögen der tran- szendentalen Einbildungskraft, nichts anderes als die ursprüng- liche Zeit. Diese Verwurzelung in der Zeit ist es allein, kraft deren die transzendentale Einbildungskraft uberhaupt die Wurzel der Transzendenz sein kann. (GA3, 196) 
necesaria de la triple síntesis a priori, la unidad de las intuiciones empíricas, la formación de conceptos y elaboración de juicios -argumento número 6 del esquema anterior.

b) la Imaginación pura es la raíz de la trascendencia que reúne, originariamente, los elementos provenientes de la sensibilidad y entendimiento. Consideremos lo siguiente:

La problemática de la deducción trascendental y del esquema puede aclararse solamente si la imaginación trascendental se deja comprobar como raíz de la trascendencia. La pregunta acerca de la síntesis pura, planteada allí, tiende hacia una unión original, en la que el elemento unitivo debe de estar previamente en el nivel de los elementos por unir. Pero esta formación de una unidad originaria no es posible sino a condición de que el elemento unitivo, por su esencia misma, haga surgir los elementos por unir. El carácter de raíz del fundamento establecido, hace comprensible, según esto, la originariedad de la síntesis pura, es decir, su hacer surgir (GA3, 140-141) ${ }^{26}$.

Heidegger remarca aquí el rol fundador de la imaginación trascendental como el elemento más originario del conocimiento sintético a priori. En la primera edición de la Crítica, Kant definía a la imaginación como la facultad que media entre las facultades del entendimiento y la sensibilidad ${ }^{27}$. Sin embargo, en su segunda edición, esta característica es eliminada por Kant. Aquello que surge como un objeto empírico, señala Heidegger, reconoce su unidad a nivel puro. Pues bien, el elemento que posee la capacidad de unir originariamente todas las representaciones, es la imaginación trascendental. Luego, es esta la facultad que confiere una unidad entre la intuición empírica y la síntesis pura ${ }^{28}$. Así, Heidegger

${ }^{26}$ Wenn sich die transzendentale Einbildungskraft als Wurzel der Transzendenz nachweisen läßt, dann gewinnt die Proble- matik der transzendentalen Deduktion und des Schematismus erst ihre Durchsichtigkeit. Die dort gestellte Frage nach der reinen Synthesis zielt auf eine ursprüngliche Einigung, in der das Einigende den zu einigenden Elementen im vorhinein ge- wachsen sein muß. Dieses Bilden einer ursprünglichen Einheit ist aber nur so möglich, daß das Einigende seinem Wesen nach das zu Einigende entspringen laßßt. Der Wurzelcharakter des gelegten Grundes macht demnach erst die Ursprünglichkeit der reinen Synthesis, d. h. ihr Entspringenlassen, verständlich. (GA3, 140-141)

${ }^{27}$ Tenemos, pues, una imaginación pura, como una facultad fundamental del alma humana ${ }^{27}$ que sirve a priori de fundamento de todo conocimiento. Por medio de ella enlazamos, por un lado, lo múltiple de la intuición, con, por otro lado, la condición de la unidad necesaria de la apercepción pura. Los dos extremos, a saber, sensibilidad y entendimiento, deben articularse necesariamente por medio de esta función trascendental de la imaginación; pues de otro modo, aquélla daría, ciertamente, fenómenos, pero no objetos de un conocimento empírico, y por tanto [no daría] experiencia alguna. (A 124). Esta cita es eliminada en la segunda edición. Compárese con (B 151-152 y B 164).

${ }^{28}$ Esta interpretación es tan polémica como la anterior, referida a la división analítica de la apercepción trascendental respecto del tiempo. La raíz desconocida entre sensibilidad y entendimiento, parte de la certeza de la intuición empírica; es decir: tal como Kant define a las 
erige a la imaginación trascendental como una facultad que se sitúa en la génesis del conocimiento a priori y que confiere unidad a los elementos heterogéneos de la sensibilidad y de las categorías.

\section{Conclusiones}

Heidegger sostiene que Kant retrocede ante la facultad de la imaginación trascendental. Las razones de este retroceso corresponderían a un acto deliberado: a juicio de Heidegger, Kant tenía claridad sobre la posibilidad de una fundamentación más originaria del conocimiento a priori; sin embargo, aquello no constituía una parte importante de su propósito más inmediato. ¿Cómo iba Kant a admitir que una facultad inferior de la sensibilidad constituye la esencia de la razón? Definitivamente, si la razón pura se convierte en imaginación trascendental ¿no nos conduce esto a un abismo? Heidegger lo afirma del siguiente modo:

¿Acaso la Crítica de la razón pura no se priva a sí misma de su tema, si la razón pura se convierte en imaginación trascendental? No nos conduce esta fundamentación a un abismo? Kant llevó la posibilidad de la metafísica al borde de este abismo. Vio lo desconocido y tuvo que retroceder $(\mathrm{GA} 3,167-8)^{29}$.

La respuesta a la pregunta sobre los fundamentos para las variaciones que Kant establece en la segunda edición de la Crítica de la razón pura es una sola: Kant retrocede ante un fundamento que excedería los límites de su sistema. Este fundamento es la función de la imaginación trascendental.A partir de lo anterior, podemos señalar que para Heidegger, la facultad de la imaginación trascendental es el lugar específico en el que Kant se enfrenta a aquella raíz desconocida ${ }^{30}$ dentro de los límites de su propio pensamiento ${ }^{31}$ :

facultades en la primera edición de la Crítica de la razón pura, existiría un vínculo desconocido entre ambas facultades que nos permite comprender las intuiciones. Sin embargo, la tarea de revelar la raíz común entre sensibilidad y entendimiento iría más allá de los límites que el propio Kant ha delimitado para su filosofía trascendental.Luego, la frase "tal vez" de A15/B29 admitiría meramente la posibilidad lógica de su existencia. Sin embargo, no existe prueba alguna de su existencia concreta. Pues bien, para Heidegger la raíz desconocida es, en la primera Crítica, la imaginación pura o trascendental. Y es ésta facultad la que requeriría de una interpretación ontológica. Véase: Henrich (1955)

29 "Wird der „Kritik der reinen Vernunft" nicht durch sie selbst das Thema entzogen, wenn reine Vernunft zur transzendentalen Einbildungskraft umschlägt? Fuihrt diese Grundlegung nicht vor einen Abgrund? Kant brachte die „Möglichkeit” der Metaphysik im Radikalismus seines Fragens vor diesen Abgrund. Er sah das Unbekannte. Er mußte zurückweichen” (GA 3, 167-8).

${ }^{30}$ Como introducción o nota preliminar, sólo parece necesario indicar que existen dos troncos del conocimiento humano, los cuales proceden acaso de una raíz común, pero desconocida para nosotros: la sensibilidad y el entendimiento (Crítica de la razón pura A15/B29). "'Nur so viel scheint 
Esta constitución originaria de la esencia del hombre, "enraizada" en la imaginación trascendental, es lo "desconocido", que Kant debe haber entrevisto, pues habló de una "raíz desconocida para nosotros". Lo desconocido no es aquello de lo que no sabemos absolutamente nada, sino aquello que, en lo conocido, se nos impone como un elemento de inquietud. Sin embargo, Kant no llevó a cabo la interpretación más originaria de la imaginación trascendental, ni siquiera la emprendió, a pesar de los indicios claros, que fue el primero en reconocer, para un análisis de esta índole. Por el contrario: Kant retrocedió ante esta raíz desconocida ${ }^{32}(\mathrm{GA3}, 113)$.

Heidegger argumenta que en la segunda edición de la Crítica de la razón pura, la facultad de la imaginación trascendental pierde toda su fuerza interpretativa (GA3, 249-250). ${ }^{33}$ Ahora bien, si tal como argumenta Heidegger, en la segunda edición de la Crítica de la razón pura, Kant retrocede ante una raíz desconocida que surgiría a partir de su propio pensamiento, se podría argumentar que la variación que sufre

zur Einleitung, oder Vorerinnerung, nötig zu sein, daß es zwei Stämme der menschlichen Erkenntnis gebe, die vielleicht aus einer gemeinschaftlichen, aber uns unbekannten Wurzel entspringen, nämlich Sinnlichkeit und Verstand, durch deren ersteren uns Gegenstände gegeben, durch den zweiten aber gedacht werden" (Crítica de la razón pura A15/B29).

31 Véase: Dieter Henrich $(1955,19)$. "Heidegger insiste en que la verdadera dinámica de la Crítica tiene que verse en la fuerza de la mirada de Kant hacia ese "desconocido", dado que lo desconocido no es aquello de lo que no sabemos nada, sino lo que nos llega como lo inquietante de lo que es conocido. . . Así, cualquier persona que intente entrar en un diálogo con Heidegger con respecto a esta suposición subyacente, se refiere a la interpretación de ese pasaje en Kant".

32 "Diese ursprüngliche, in der transzendentalen Einbildungskraft "gewurzelte" Wesensverfassung des Menschen ist das „Unbekannte", in das Kant hineingeblickt haben muß, wenn er von der „uns unbekannten Wurzel" sprach. Denn das Unbekannte ist ja nicht das, wovon wir schlechthin nichts wissen, sondern was uns im Erkannten als das Beunruhigende entgegendrängt. Doch Kant hat die ursprünglichere Auslegung der transzendentalen Einbildungskraft nicht durchgefuhrt, ja nicht einmal dazu angesetzt, trotz der deutlichen, von ihm selbst erstmals erkannten Vorzeichnungen zu einer solchen Analytik. Im Gegenteil: Kant ist vor dieser unbekannten Wurzel zurückgewichen. (GA 3, 113).

${ }^{33}$ Sin embargo, tal como argumenta Llewelyn, T. (2000) quien señala que sí hay referencias a la Imaginación productiva en la segunda edición de la Crítica, cuestión que no es considerada por Heidegger en su interpretación (por ejemplo, en B152 Kant refiere a la imaginación productiva para contrastarla con la imaginación reproductiva). Sin embargo, Heidegger afirmaría que en la segunda edición, la imaginación trascendental está presente solo en el nombre; y que, además, sólo señala a la síntesis empírica del Entendimiento. Véase: GA3, 249-250. En opinión de Llewelyn, el pesimismo de Heidegger sobre la Deducción Trascendental en B se basa en dos argumentos: El primero es no considerar la posibilidad de que la imaginación -de la primera edición de la Crítica, puede ser una función del entendimiento, que se refiere a la comprensión en el sentido amplio; que provendría de una conexión con aspectos más fundamentales como la mente o el alma. Al contrario, la su edición de la Crítica, cierra esta posibilidad, dándole a la facultad del entendimiento un sentido opuesto an concepto de comprensión que podríamos otorgarle a la imaginación. Así, la primera edición de la Crítica, a pesar de su oscuridad y contradicciones, podría hacer una gran contribución a la comprensión de la contemplación de las bellas artes en la tercera Crítica. 
la facultad de la imaginación en la segunda edición de la Crítica es un intento consciente de Kant para ocultar un aspecto problemático de su pensamiento.

Ahora bien: ¿en qué medida la "raíz desconocida" de la imaginación trascendental de la primera edición de la Crítica de la razón pura, pertenece a los aspectos más esenciales de la filosofía trascendental? Si bien, Heidegger argumenta que lo "desconocido" (das Unbekannte) no es aquello de lo que no sabemos absolutamente nada, sino aquello que, en lo conocido, se nos impone como un elemento de inquietud $^{34}$-y que con ello busca argumentar que aquella raíz desconocida ${ }^{35}$ del conocimiento surge de un lugar que pertenece al sistema filosófico kantiano el argumento parece ser insuficiente. Esto queda de manifiesto en los sucesivos Prólogos del Kantbuch en 1968 y 1973 -respectivamente: Heidegger declarará que su interpretación de Kant durante la segunda mitad de la década de 1920 fue un refugio para desarrollar su propio pensamiento.

El texto de Kant se convirtió en un refugio, y en Kant busqué a un portavoz para la pregunta ontológica por mí planteada (GA3 xiv/xvii) ${ }^{36}$

El refugio así determinado significaba que la "Crítica de la razón pura" se interpretaba en el círculo de la cuestión de "Ser y Tiempo", pero de hecho la pregunta le era ajena a Kant, aunque la cuestión estaba condicionada subrepticiamente (GA3, xiv) ${ }^{37}$

Las anteriores referencias, dejan entrever la violencia interpretativa de Heidegger y su distanciamiento de la filosofía tarscendental. Por su parte, si bien Kant es -de acuerdo a Heidegger- "el primero y único que recorrió en su investigación un trecho del camino hacia la dimensión de la temporariedad, o que, más bien, se dejó arrastrar hacia ella por la fuerza de los fenómenos mismos" 38 (GA2, 23), la filosofía trascendental no consigue penetrar en el problema general de Ser y Tiempo. La omisión de la pregunta por el ser en Kant, tendrá otro significado en la filosofía trascendental: ella estará dirigida por la pregunta por el ente y por la posibilidad

\footnotetext{
${ }^{34}$ Denn das Unbekannte ist ja nicht das, wovon wir schlechthin nichts wissen, sondern was uns im Erkannten als das Beunruhigende entgegendrängt $(\mathrm{GA} 3,113)$

${ }^{35}$ Aquella raìz desconocida es el lugar donde las facultades de sensibilidad y entendimiento se originan. Véase: (A15/B29).

${ }^{36}$ Kants Text wurde eine Zuflucht, bei Kant einen Fürsprecher für die von mir gestellte Seinsfrage zu suchen (GA3 xiv/xvii). Desgraciadamente, esta cita no está recopilada en la traducción al español de GA 3

37 Die dergestalt bestimmte Zuflucht fuhrte dazu, daß die „Kritik der reinen Vernunft" im Gesichtskreis der Fragestellung von "Sein und Zeit" ausgelegt, in Wahrheit jedoch der Frage Kants eine ihr fremde, wenngleich sie bedingende Fragestellung untergelegt wurde (GA3, XIV)

${ }^{38}$ Der Erste und Einzige, der sich eine Strecke untersuchenden Weges in der Richtung auf Dimension der Temporalität bewegte, bzw. Sich durch den Zwang der Phänomene selbst dahin drängen ließ, ist Kant. (GA2, 23)
} 
de su conocimiento. La filosofía trascendental carece así de una analítica ontológica de la subjetividad y de un concepto de tiempo -que se determine como el origen último de toda intuición; dos aspectos que el pensamiento temprano de Heidegger parece pasar por alto.

\section{Bibliografía}

\section{Fuentes principales:}

- Immanuel Kant:

Las citas de la obra de Immanuel Kant han sido extraídas de las obras completas Akademie-Ausgabe en alemán. Las citas se encuentran en línea, en el sitio web: www.korpora.org

En español:

Crítica de la razón pura (1999). Trad. Pedro Ribas, Alfaguara: Madrid.

- Martin Heidegger

GA 2. Sein und Zeit, ed. F. W. von Herrmann, (1927).

GA 3. Kant und das Problem der Metaphysik, ed. F. W. von Herrmann, (1929).

GA 25. Phänomenologische Interpretation von Kants Kritik der reinen Vernunft (Winter semester 1927/28), ed. I. Görland, (1977).

En español:

Ser y Tiempo, (2015) traducción de Jorge Eduardo Rivera, Editorial Universitaria, Santiago de Chile.

Kant y el problema de la metafísica, (1996) Fondo de Cultura Económica, México.

\section{$\underline{\text { Fuentes secundarias }}$}

Álvarez. W. (2014) "Las formas de la imaginación en Kant". Praxis Filosófica Nueva serie, No. 40, enero-junio 2015: 35-62.

Grene, M. (1957) Martin Heidegger. London: Bowes \& Bowes.

Hartnack. J. (2006) La teoría del conocimiento de Kant. Ediciones Cátedra, Madrid.

Heinrich, D. (1955) “Über die Einheit der Subjektivität, Rez. Zu Kant und das Problem der Metaphysik von M. Heidegger" in Philosophische Rundschau, 3. 
Kisiel, (1993) The Genesis of Heidegger's "Being and Time". Berkeley: The University of California Press.

Langan, T. (1962) 'Foreword', Kant and the Problem of Metaphysics, by Martin Heidegger, trans. J.S. Churchill. Bloomington: Indiana University Press.

Löwith, K. (1960) Heidegger: Denker in dürftiger Zeit. Göttingen: Vandenhoeck \& Ruprecht.

Llewelyn, T. (2000) The HypoCritical Imagination. Between Kant and Levinas, London: Routledge.

Richardson, W. (1967) Heidegger: Through Phenomenology to Thought. The Hague: Martinus Nijhoff.

Rosales. A. (2009) Ser y subjetividad en Kant. Sobre el origen subjetivo de las categorías. Editorial Biblos, Buenos Aires.

Shreover, CH. (1984) "Heidegger's Use of Kant in Being and Time", in Seebohm and Kockelmans, Kant and Phenomenology, Washington, DC: The Center for Advanced Research in Phenomenology.

Van Buren, J. (1994) The young Heidegger: rumor of the hidden King, Studies in Continental thought. Bloomington: Indiana University Press. 